\title{
Smoking cessation and survival in lung, upper aero-digestive tract and bladder cancer: cohort study
}

\author{
C Koshiaris ${ }^{1}$, P Aveyard ${ }^{*}, 1$, J Oke ${ }^{1}$, R Ryan $^{2}$, L Szatkowski ${ }^{3}$, R Stevens ${ }^{1}$ and A Farley ${ }^{2}$ \\ ${ }^{1}$ Nuffield Department of Primary Care Health Sciences, UK Centre for Tobacco and Alcohol Studies, University of Oxford, New \\ Radcliffe House, Radcliffe Observatory Quarter, Woodstock Road, Oxford OX2 6GG, UK; ${ }^{2}$ Institute of Applied Health Research, \\ University of Birmingham, Edgbaston, Birmingham B15 2TT, UK and ${ }^{3}$ Division of Epidemiology and Public Health, University of \\ Nottingham, Clinical Sciences Building, Nottingham City Hospital, Nottingham NG5 1PB, UK
}

Background: The aim was to examine the association between smoking cessation and prognosis in smoking-related cancer as it is unclear that cessation reduces mortality.

Methods: In this retrospective cohort study from 1999 to 2013, we assessed the association between cessation during the first year after diagnosis and all-cause and cancer-specific mortality.

Results: Of 2882 lung, 757 upper aero-digestive tract (UAT) and 1733 bladder cancer patients $27 \%, 29 \%$ and $21 \%$ of lung, UAT and bladder cancer patients quit smoking. In lung cancer patients that quit, all-cause mortality was significantly lower (HR: 0.82 (0.740.92), while cancer-specific mortality (HR: $0.89(0.76-1.04)$ and death due to index cancer (HR: 0.90 (0.77-1.05) were non-significantly lower. In UAT cancer, all-cause mortality (HR: 0.81 (0.58-1.14), cancer-specific mortality (HR: 0.84 (0.48-1.45), and death due to index cancer (HR: 0.75 (0.42-1.34) were non-significantly lower. There was no evidence of an association between quitting and mortality in bladder cancer. The HRs were $1.02(0.81-1.30)$ for all-cause, $1.23(0.81-1.86)$ for cancer specific, and 1.25 (0.71-2.20) for death due to index cancer. These showed a non-significantly lower risk in sensitivity analyses.

Conclusions: People with lung and possibly UAT cancer who quit smoking have a lower risk of mortality than people who continue smoking.

Around a fifth of all cancers worldwide are caused by smoking (Ezzati et al, 2005), and smoking-related tumours commonly develop in the lung, upper aero-digestive tract (UAT) and bladder (Thun et al, 2009) (US Surgeon General, 2014b). Although 5-year survival rates for lung cancer are low, as most patients present in late stages (Verdecchia et al, 2007; Walters et al, 2013), around 70\% of patients who are treated curatively survive for 5 years (UK. CR, 2016). The proportion of people with curatively treated cancer is likely to increase with the advent of computerised tomographybased lung cancer screening. In upper aerodigetsive tract (UAT) and bladder cancer, the European mean age-standardised 5-year survival rates are $\sim 40$ and $70 \%$, respectively (De Angelis et al,
2014). Thus, there is a large group of people with smoking-related cancer who may benefit from additional interventions to improve prognosis.

There is some evidence that quitting smoking after diagnosis of smoking-related cancers may be associated with improved prognosis, particularly in patients who have been diagnosed in early stages (Aveyard et al, 2002; Parsons et al, 2010; US Surgeon General, 2014b). However, many of these studies have methodological limitations such as a small sample size and unclear definitions of smoking status (Gritz et al, 2014). In addition, most studies compare the prognosis in patients who are smoking at diagnosis to those who have quit some time before or who have 
never smoked. Few studies have focused on the prognostic benefit of quitting at or soon after diagnosis (Land, 2012; Balough et al, 2014; US Surgeon General, 2014b).

Many patients with smoking-related cancers are still smoking at diagnosis (Cooley et al, 2009; Park et al, 2012; Warren et al, 2013a) and support to quit is not routinely offered as part of cancer care (Murray et al, 2012; Warren et al, 2013b). If quitting soon after diagnosis improved prognosis, this would increase the clinical imperative to offer patients smoking cessation interventions to improve their chances of survival. Unlike many treatments for cancer, smoking cessation treatment is safe and has mild adverse effects. In order to investigate if quitting after diagnosis has prognostic benefits, we estimated the association between quitting and all-cause mortality in lung, UAT and bladder cancer patients using a large data set of the routinely-collected primary care data. Cessation reduces mortality from cardiorespiratory disease and thus cessation would be expected to reduce mortality from this cause. We therefore investigated whether some of the benefit could be due to prevention of cancer progression by examining the association between quitting and death due to cancer.

\section{MATERIALS AND METHODS}

We conducted a retrospective cohort study using routinelycollected UK primary care records from the Clinical Practice Research Datalink (CPRD) (www.cprd.com). The protocol was approved by the Independent Scientific Advisory Committee (ISAC) for MHRA database research (reference no: 14_105), and was made available during the peer review process. Patients with a first diagnosis of lung, UAT and bladder cancers between 1999 and 2013 who smoked at diagnosis, survived for one year, had been registered with a practice for at least one year and had at least one year of follow-up data were included in the cohort. UAT cancers mainly included cancers that occur in the mouth and throat, and full definitions, and the Read codes used for each cancer are provided in Appendix 1 (HSCIC, 2014). We restricted the analysis to patients that survived for at least 1 year to limit confounding by stage of cancer at diagnosis. Stage was not recorded in most cases. People with advanced cancer-treated palliatively may be less likely to stop smoking and are more likely to die, thus confounding the association between smoking cessation and mortality. As many such patients die within a year, restricting the analysis in this way limited confounding. Patients were followed-up until the end of 2013 or death, or were censored if they moved practice. In 2013, the CPRD database contained records from 4.4 million live patients in 674 practices, which represented $6.9 \%$ of the UK population (Herrett et al, 2015). The first version of the protocol was amended to exclude people with thyroid cancer because this is not a smoking-related head and neck cancer.

Patients were defined as smokers at diagnosis if they were recorded as smoking on the last occasion smoking status was updated within the 3 years prior to diagnosis. People were classified as having stopped smoking or continued smoking during the first year of follow-up if their last record during that period recorded either state. Some people did not have their smoking status updated after diagnosis, and we conducted sensitivity analyses to examine the impact of this on the findings.

Survival time was calculated as the time from the end of the first year after diagnosis until outcome occurrence (all-cause mortality, cancer-specific mortality or death due to index cancer). The fact of death was taken from the CPRD record and also from the UK national system of recording death provided by the Office for National Statistics (ONS) and this was used for all-cause mortality analyses. The CPRD database does not record cause of death but ONS does. Thus, for those patients in practices where the ONS death data could be linked, we examined cancer-specific mortality and death due to index cancer. To do so, the ONS data were linked to each person's CPRD data. In the protocol, we planned to investigate development of a recurrence or development of a second primary tumour but were unable to do this as these outcomes were poorly recorded.

Survival curves were generated with the Kaplan-Meier plot method for each outcome. We used Cox proportional hazard regression models to compare differences in survival between people who stopped and people who continued smoking in each cancer group. The proportional hazards assumption was examined by the use of log-log plots and Schoenfeld residuals. The results are presented as hazard ratios with $95 \%$ confidence intervals, and we use the term non-significant as shorthand to mean that the $95 \%$ confidence intervals included unity. In the main analyses, we adjusted for age, gender, socio-economic status (SES), comorbidity (asthma, chronic kidney disease (CKD), chronic obstructive pulmonary disease (COPD), diabetes, hypertension, peripheral arterial disease (PAD), stroke, psychoses), treatment and alcohol consumption. Patients whose smoking status after diagnosis was missing, were included as an additional exposure category. Due to missing data on smoking status after diagnosis, alcohol status and SES we used multiple imputation (MI) models to impute these data. We used the mi command in STATA 14 with 20 imputed datasets, including the baseline and clinical characteristics, outcome and the Nelson-Aalen estimator of the cumulative hazard function (White and Royston, 2009).

Sensitivity analyses were conducted to investigate the robustness of MI models. Sensitivity analyses comprised unadjusted analysis, full case analysis and full case analysis, where patients that did not have their smoking status updated within the year following diagnosis were classified as continued smokers. We performed two additional sensitivity analyses but do not show the data as the results of these analyses were very similar to the main results. First, we excluded covariates with missing data (alcohol status and SES). Second, in response to a referee, we adjusted for year of diagnosis, which made no material difference, and then added a multiplicative interaction term between smoking status and year of diagnosis, and this was not significant in any analysis.

\section{RESULTS}

During the study period, there were a total of 42112 incident cancer cases (lung $n=27615$, UAT $n=3248$, bladder $n=11249$ ). Information regarding smoking status at diagnosis was available for $81 \%$ of these cases (lung $83 \%$, UAT $78 \%$, bladder $79 \%$ ), and we assumed that patients with missing status were either never smokers, or long-term ex-smokers, consistent with the rules GPs for updating smoking status (Marston et al, 2014). On the basis of this assumption, 36\%,35\% and 20\% of lung, UAT and bladder cancer patients were smoking at diagnosis. We included in our analyses patients who smoked at diagnosis and who had survived for at least 1 year. This included 2882 people with lung cancer (27\% quit, 39\% continued, 34\% unknown), 757 people with UAT cancer (29\% quit, 37\% continued, 34\% unknown) and 1733 people with bladder cancer ( $21 \%$ quit, $49 \%$ continued, $30 \%$ unknown). As not every practice in the CPRD database is linked to ONS for the cause of death analyses, the cohorts for the analyses of cancerspecific mortality and death due to index cancer were smaller (lung cancer $n=1635$; UAT cancer $n=428$; bladder cancer $n=1013$ ) (Figure 1).

The baseline demographic characteristics were similar across smoking exposure groups (quit during first year, continued during first year, no smoking update during first year) for each cancer group. There were some imbalances in the presence of 

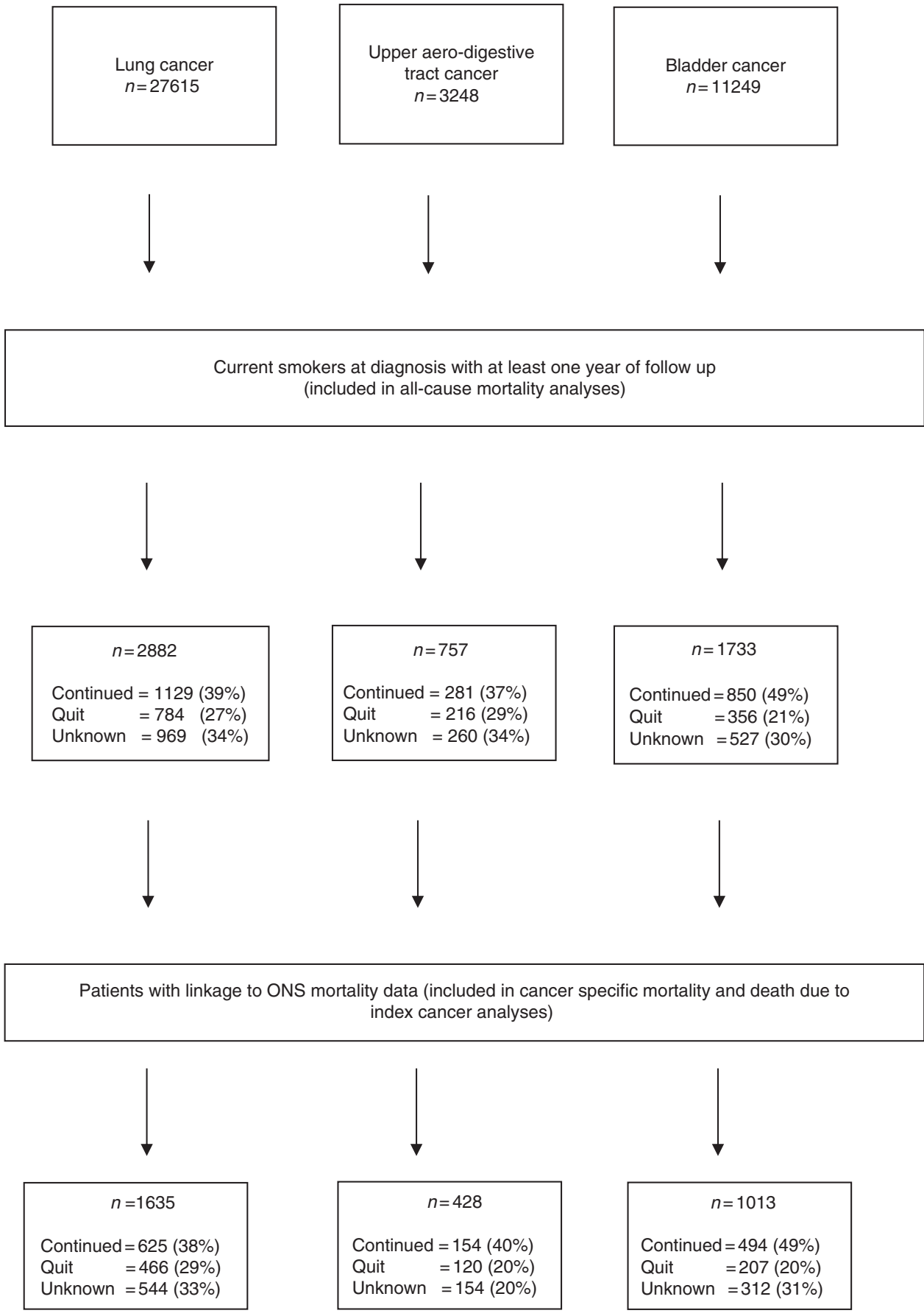

Figure 1. Flow of participants through the study.

comorbidities across exposure groups for each cancer group (Table 1). A higher proportion of patients who quit smoking received surgery. However, these baseline characteristics were controlled for in the analyses.

Association between smoking status after diagnosis and allcause mortality. Lung cancer patients who quit smoking had a significantly lower risk of all-cause mortality compared with patients who continued to smoke (unadjusted HR: 0.71 (95\% CI: 0.63-0.79), adjusted HR: 0.82 (95\% CI: 0.74-0.92)) (Table 2). Median survival (from 1 year after diagnosis) for patients who continued smoking was 1.08 years (95\%CI: 0.94-1.24), and was 1.97 years (1.68-2.26) for patients who quit. In UAT, quitting smoking was associated with a non-significantly lower risk of mortality, which was unchanged after adjustment (unadjusted HR:
0.80 (0.60-1.08), adjusted HRL 0.81 (0.58-1.14)). There was no evidence of an association between quitting and mortality in patients with bladder cancer (unadjusted HR: 0.91 (95\% CI: 0.73-1.14), adjusted HR: $1.02(0.81-1.30)$ ) (Figure 2). The sensitivity analysis with different assumptions produced very similar results to these for all cancers (Table 2).

Association between smoking status after diagnosis and cancerspecific mortality. Of all the people diagnosed with lung cancer, $86 \%$ died of lung cancer. Quitting smoking after a diagnosis of lung cancer was associated with lower cancer-specific mortality (unadjusted HR: $0.73(0.62-0.85)$ ), but this became non-significant after adjustment (HR: $0.89(0.76-1.04)$ ) (Table 2). Less than two thirds of the deaths after UAT and bladder cancer were due to cancer (65 and 59\%, respectively). Quitting smoking after diagnosis 
Table 1. Baseline characteristics of patients with lung, bladder and upper aero-digestive tract cancer by smoking exposure status

\begin{tabular}{|c|c|c|c|c|c|c|c|c|c|}
\hline \multirow[b]{2}{*}{ Characteristics } & \multicolumn{3}{|c|}{ Lung cancer } & \multicolumn{3}{|c|}{ Upper aero-digestive tract cancer } & \multicolumn{3}{|c|}{ Bladder cancer } \\
\hline & $\begin{array}{c}\text { Continued } \\
\text { smoking } \\
\left(\begin{array}{c}N=1129 \\
39 \%)\end{array}\right.\end{array}$ & $\begin{array}{c}\text { Quit } \\
\text { smoking } \\
\left(\begin{array}{c}N=784 \\
27 \%)\end{array}\right.\end{array}$ & $\begin{array}{c}\text { Status not } \\
\text { updated } \\
\begin{array}{c}\text { (N=969, } \\
34 \%)\end{array}\end{array}$ & $\begin{array}{c}\text { Continued } \\
\text { smoking } \\
\left(\begin{array}{c}N=281 \\
37 \%)\end{array}\right.\end{array}$ & $\begin{array}{c}\text { Quit } \\
\text { smoking } \\
\left(\begin{array}{c}N=216, \\
29 \%)\end{array}\right.\end{array}$ & $\begin{array}{l}\text { Status not } \\
\text { updated } \\
\left(\begin{array}{c}N=260 \\
34 \%)\end{array}\right.\end{array}$ & $\begin{array}{l}\text { Continued } \\
\text { smoking } \\
\left(\begin{array}{c}N=850 \\
49 \%)\end{array}\right.\end{array}$ & $\begin{array}{c}\text { Quit } \\
\text { smoking } \\
\left(\begin{array}{c}N=356 \\
21 \%)\end{array}\right.\end{array}$ & $\begin{array}{c}\text { Status not } \\
\text { updated } \\
\begin{array}{c}(N=527 \\
30 \%)\end{array}\end{array}$ \\
\hline Gender (\% male) & $588(52.1 \%)$ & $364(46.4 \%)$ & $484(49.9 \%)$ & $197(70.1 \%)$ & $143(66.2 \%)$ & $181(69.6 \%)$ & $618(72.7 \%)$ & $269(75.6 \%)$ & $418(79.3 \%)$ \\
\hline Age (mean, s.d. years) & $67.1(9.97)$ & $66.3(9.04)$ & $65.8(10.4)$ & $59.65(10.86)$ & $61(10.83)$ & $59.96(11.2)$ & $67.49(10.7)$ & $65.39(10.8)$ & $66.14(11.5)$ \\
\hline $\begin{array}{l}\text { Patients with ONS } \\
\text { linkage }\end{array}$ & $625(55.4 \%)$ & $466(59.4 \%)$ & $544(56.1 \%)$ & $154(54.8 \%)$ & $120(55.6 \%)$ & $154(59.2 \%)$ & $494(58.1 \%)$ & $207(58.15 \%)$ & $312(59.2 \%)$ \\
\hline $\begin{array}{l}\text { Alcohol status } \\
\text { Non drinkers } \\
\text { Ex-drinkers } \\
\text { Light drinkers } \\
\text { Moderate drinkers } \\
\text { Heavy drinkers } \\
\text { Drinkers (unknown } \\
\text { amount) } \\
\text { No record found }\end{array}$ & $\begin{array}{l}264(23.4 \%) \\
103(9.1 \%) \\
101(9 \%) \\
100(8.9 \%) \\
30(2.7 \%) \\
60(5.3 \%) \\
471(41.7 \%)\end{array}$ & $\begin{array}{l}180(22.9 \%) \\
54(6.9 \%) \\
55(7 \%) \\
63(8 \%) \\
10(1.3 \%) \\
30(3.8 \%) \\
392(50 \%)\end{array}$ & $\begin{array}{l}216(22.3 \%) \\
49(5 \%) \\
75(7.7 \%) \\
65(6.7 \%) \\
20(2.1 \%) \\
25(2.6 \%) \\
519(53.6 \%)\end{array}$ & $\begin{array}{l}36(12.8 \%) \\
22(7.8 \%) \\
18(6.4 \%) \\
39(13.9 \%) \\
26(9.3 \%) \\
18(6.4 \%) \\
122(43.4 \%)\end{array}$ & $\begin{array}{l}35(16.2 \%) \\
13(6 \%) \\
25(11.6 \%) \\
29(13.4 \%) \\
11(5.1 \%) \\
8(3.7 \%) \\
95(43.8 \%)\end{array}$ & $\begin{array}{c}38(14.6 \%) \\
9(3.5 \%) \\
24(9.2 \%) \\
37(14.2 \%) \\
16(6.2 \%) \\
13(5 \%) \\
123(47.3 \%)\end{array}$ & $\begin{array}{l}228(26.8 \%) \\
85(10 \%) \\
65(7.7 \%) \\
79(9.3 \%) \\
16(1.9 \%) \\
28(3.3 \%) \\
349(41.1 \%)\end{array}$ & $\begin{array}{c}96(27 \%) \\
22(6.2 \%) \\
35(9.8 \%) \\
29(8.2 \%) \\
4(1.1 \%) \\
25(7 \%) \\
145(40.7 \%)\end{array}$ & $\begin{array}{c}126(23.9 \%) \\
20(3.8 \%) \\
55(10.4 \%) \\
38(7.2 \%) \\
8(1.5 \%) \\
8(1.5 \%) \\
\\
272(51.6 \%)\end{array}$ \\
\hline $\begin{array}{l}\text { IMD score } \\
1 \\
2 \\
3 \\
4 \\
5 \\
\text { Missing }\end{array}$ & $\begin{array}{c}63(5.6 \%) \\
105(9.3 \%) \\
121(10.7 \%) \\
149(13.2 \%) \\
179(15.9 \%) \\
512(45.4 \%)\end{array}$ & $\begin{array}{l}68(8.7 \%) \\
88(11.2 \%) \\
76(9.7 \%) \\
110(14 \%) \\
124(15.8 \%) \\
318(40.6 \%) \\
\end{array}$ & $\begin{array}{c}90 \text { (9.3\%) } \\
104(10.7 \%) \\
116(12 \%) \\
124(12.8 \%) \\
102(10.5 \%) \\
433(44.7 \%)\end{array}$ & $\begin{array}{c}9(3.2 \%) \\
26(9.3 \%) \\
31(11 \%) \\
47(16.7 \%) \\
41(14.6 \%) \\
127(45.2 \%)\end{array}$ & $\begin{array}{l}15(6.9 \%) \\
20(9.3 \%) \\
30(13.9 \%) \\
26(12 \%) \\
26(12 \%) \\
99(45.8 \%)\end{array}$ & $\begin{array}{c}19 \text { (7.3\%) } \\
29 \text { (11.2\%) } \\
29(11.2 \%) \\
38(14.6 \%) \\
34(13.1 \%) \\
111(42.7 \%)\end{array}$ & $\begin{array}{c}64(7.5 \%) \\
98(11.5 \%) \\
100(11.8 \%) \\
120(14.1 \%) \\
105(12.4 \%) \\
363(42.7 \%)\end{array}$ & $\begin{array}{c}36(10.1 \%) \\
54(15.2 \%) \\
45(12.6 \%) \\
47(13.2 \%) \\
23(6.5 \%) \\
151(42.4 \%)\end{array}$ & $\begin{array}{c}55 \text { (10.4\%) } \\
72(13.7 \%) \\
61(11.6 \%) \\
77(14.6 \%) \\
45 \text { (8.5\%) } \\
217(41.2 \%) \\
\end{array}$ \\
\hline $\begin{array}{l}\text { Comorbidities } \\
\text { Asthma } \\
\text { CKD } \\
\text { COPD } \\
\text { Diabetes } \\
\text { Hypertension } \\
\text { Peripheral arterial } \\
\text { disease } \\
\text { Stroke } \\
\text { Psychosis }\end{array}$ & $\begin{array}{c}127(11.2 \%) \\
103(9.1 \%) \\
370(32.8 \%) \\
96(8.5 \%) \\
263(23.3 \%) \\
103(9.1 \%) \\
102(9 \%) \\
12(1.1 \%)\end{array}$ & $\begin{array}{c}74(9.4 \%) \\
62(7.9 \%) \\
196(25 \%) \\
85(10.9 \%) \\
171(21.8 \%) \\
50(6.4 \%) \\
49(6.2 \%) \\
6(0.8 \%)\end{array}$ & $\begin{array}{c}56(5.8 \%) \\
41(4.2 \%) \\
143(14.7 \%) \\
30(3.1 \%) \\
130(13.4 \%) \\
40(4.1 \%) \\
41(4.2 \%) \\
7(0.7 \%)\end{array}$ & $\begin{array}{l}21(7.5 \%) \\
12(4.3 \%) \\
41(14.6 \%) \\
20(7.1 \%) \\
42(14.9 \%) \\
14(5 \%) \\
6(2.1 \%) \\
2(0.7 \%)\end{array}$ & $\begin{array}{l}11(5.1 \%) \\
8(3.7 \%) \\
27(12.5 \%) \\
14(6.5 \%) \\
61(28.2 \%) \\
10(4.6 \%) \\
10(4.6 \%) \\
2(0.9 \%)\end{array}$ & $\begin{array}{c}5(1.9 \%) \\
9(3.5 \%) \\
20(7.6 \%) \\
5(1.9 \%) \\
27(10.4 \%) \\
8(3.1 \%) \\
5(1.9 \%) \\
1(0.4 \%)\end{array}$ & $\begin{array}{c}67(7.9 \%) \\
85(10 \%) \\
140(16.5 \%) \\
115(13.5 \%) \\
223(26.2 \%) \\
62(7.3 \%) \\
57(6.7 \%) \\
10(1.2 \%)\end{array}$ & $\begin{array}{l}33(9.3 \%) \\
24(6.7 \%) \\
52(14.6 \%) \\
34(9.5 \%) \\
75(21.1 \%) \\
15(4.2 \%) \\
17(4.8 \%) \\
2(0.6 \%)\end{array}$ & $\begin{array}{l}15(2.8 \%) \\
23(4.4 \%) \\
25(4.7 \%) \\
14(2.7 \%) \\
78(14.8 \%) \\
19(3.6 \%) \\
19(3.6 \%) \\
4(0.8 \%)\end{array}$ \\
\hline $\begin{array}{l}\text { Treatment } \\
\text { Surgery } \\
\text { Chemotherapy } \\
\text { Radiotherapy }\end{array}$ & $\begin{array}{l}177(15.7 \%) \\
338(29.9 \%) \\
199(17.6 \%)\end{array}$ & $\begin{array}{r}264(33.7 \%) \\
221(28.2 \%) \\
98(12.5 \%) \\
\end{array}$ & $\begin{array}{l}134(13.8 \%) \\
309(31.9 \%) \\
173(17.9 \%)\end{array}$ & $\begin{array}{l}60(21.4 \%) \\
47(16.7 \%) \\
75(26.7 \%)\end{array}$ & $\begin{array}{l}59(27.3 \%) \\
33(15.3 \%) \\
46(21.3 \%)\end{array}$ & $\begin{array}{l}68(26.2 \%) \\
49(18.8 \%) \\
63(24.2 \%)\end{array}$ & $\begin{array}{c}60(7.1 \%) \\
113(13.3 \%) \\
33(3.9 \%)\end{array}$ & $\begin{array}{c}44(12.4 \%) \\
63(17.7 \%) \\
7(2.0 \%)\end{array}$ & $\begin{array}{l}45(8.5 \%) \\
76(14.4 \%) \\
22(4.2 \%)\end{array}$ \\
\hline
\end{tabular}

of either cancer was not significantly associated with reduced cancer-specific mortality (Table 2, Figure 3). Sensitivity analysis again showed very similar results.

Association between smoking status after diagnosis and death due to index cancer. There was no significant association between quitting smoking and death due to index cancer in lung (unadjusted HR: $0.72(0.61-0.85)$, adjusted HR: 0.90 (0.77-1.05, UAT (unadjusted HR: 0.78 (0.45-1.37), adjusted HR: $0.75(0.42-$ $1.34)$ or bladder cancer patients (unadjusted HR: 1.24 (0.77-1.99), adjusted HR: $1.25(0.71-2.20)$ ) (Table 2, Figure 4). Sensitivity analysis produced similar results for lung and UAT cancers but there was a modest difference between the multiple imputation and the full case models for bladder cancer. However, neither set of models suggested a significant increase or decrease in risk for people who stopped smoking.

\section{DISCUSSION}

A third of patients with lung and UAT cancer, and a fifth of those with bladder cancer smoked at diagnosis, and the majority continued after their diagnosis. In patients who survived for at least 1 year, smoking cessation during that first year was associated with a lower risk of all-cause mortality in lung cancer and the evidence was suggestive of a lower risk in UAT cancer. There was inconclusive evidence that quitting was associated with survival in bladder cancer. There was inconclusive evidence that smoking cessation was associated with lower mortality in each cancer type.

This study included many more people than previous studies investigating the impact of smoking cessation on survival, therefore producing more precise estimates of association. However, there were fewer people with data available on cause of death. This meant that the estimates for cancer-specific outcomes were less precise and it was not possible to be sure whether the apparent survival benefit arose from reduced deaths from cardiac and respiratory causes or from reduced deaths due to cancer in UAT cancer because the confidence intervals for cancer-specific deaths were wider. However, for lung cancer, it appears clearer that quitting smoking is associated with a lower cancer-specific mortality, mainly because the large majority of deaths were due to lung cancer, although the adjusted estimates of cancer-specific mortality (based on a subsample) were not themselves significant.

This study has some limitations. Firstly, smoking status was taken from the medical records and these may not accurately record true smoking status. Doctors did not record whether around a third of people continued or stopped smoking, though sensitivity analysis suggest the results were insensitive to this. Some people 
Table 2. Risk of all-cause mortality, cancer-specific mortality and death due to index cancer in quitters compared with continuing smokers with lung, bladder and upper aero-digestive tract cancer

\begin{tabular}{|c|c|c|c|c|c|c|c|c|c|}
\hline & $\begin{array}{l}\text { Ppts } \\
(n)\end{array}$ & $\begin{array}{l}\text { Total } \\
\text { deaths } \\
(n)\end{array}$ & $\begin{array}{c}\text { All-cause } \\
\text { mortality } \\
\mathrm{HR}(95 \% \mathrm{Cl})\end{array}$ & $\begin{array}{l}\text { Ppts } \\
(n)\end{array}$ & $\begin{array}{l}\text { Total } \\
\text { deaths } \\
(n)\end{array}$ & $\begin{array}{c}\text { Cancer- } \\
\text { specific } \\
\text { mortality } \\
\text { HR }(95 \% \mathrm{Cl})\end{array}$ & $\begin{array}{l}\text { Ppts } \\
(n)\end{array}$ & $\begin{array}{l}\text { Total } \\
\text { deaths } \\
(n)\end{array}$ & $\begin{array}{l}\text { Death due } \\
\text { to index } \\
\text { cancer } \\
\text { HR }(95 \% \mathrm{Cl})\end{array}$ \\
\hline \multicolumn{10}{|l|}{ Lung cancer } \\
\hline Unadjusted-missing exposure (extra category) & 2881 & 2016 & $0.71(0.63-0.79)$ & 1635 & 1025 & $0.73(0.62-0.85)$ & 1635 & 954 & $0.72(0.61-0.85)$ \\
\hline Primary model (MI model-alcohol, SES, exposure) ${ }^{a}$ & 2881 & 2016 & $0.82(0.74-0.92)$ & 1635 & 1025 & $0.89(0.76-1.04)$ & 1635 & 954 & $0.90(0.77-1.05)$ \\
\hline $\begin{array}{l}\text { Full case analysis with missing exposure as } \\
\text { category }{ }^{\text {a }}\end{array}$ & 835 & 617 & $0.82(0.66-1.00)$ & 835 & 529 & $0.87(0.70-1.10)$ & 835 & 496 & $0.87(0.69-1.10)$ \\
\hline $\begin{array}{l}\text { Full case analysis (classify missing exposure as } \\
\text { continued smokers) }\end{array}$ & 835 & 617 & $0.83(0.69-1.00)$ & 835 & 529 & $0.87(0.70-1.10)$ & 835 & 496 & $0.84(0.68-1.04)$ \\
\hline \multicolumn{10}{|l|}{ Upper aero-digestive tract cancer } \\
\hline Unadjusted-missing exposure (extra category) & 757 & 313 & $0.80(0.60-1.08)$ & 428 & 120 & $0.96(0.61-1.51)$ & 428 & 81 & $0.78(0.45-1.37)$ \\
\hline Primary model (MI model-alcohol, SES, exposure) ${ }^{a}$ & 757 & 313 & $0.81(0.58-1.14)$ & 428 & 120 & $0.84(0.48-1.45)$ & 428 & 81 & $0.75(0.42-1.34)$ \\
\hline $\begin{array}{l}\text { Full case analysis with missing exposure as } \\
\text { category }^{\text {a }}\end{array}$ & 233 & 106 & $0.72(0.40-1.27)$ & 233 & 71 & $0.88(0.46-1.68)$ & 233 & 49 & $0.71(0.31-1.62)$ \\
\hline $\begin{array}{l}\text { Full case analysis (classify missing exposure as } \\
\text { continued smokers) }\end{array}$ & 233 & 106 & $0.71(0.41-1.20)$ & 233 & 71 & $0.90(0.43-1.63)$ & 233 & 49 & $0.66(0.31-1.42)$ \\
\hline \multicolumn{10}{|l|}{ Bladder cancer } \\
\hline Unadjusted-missing exposure (extra category) & 1733 & 571 & $0.91(0.73-1.14)$ & 1013 & 213 & $1.23(0.86-1.74)$ & 1013 & 122 & $1.24(0.77-1.99)$ \\
\hline Primary model (MI model-alcohol, SES, exposure) ${ }^{a}$ & 1733 & 571 & $1.02(0.81-1.30)$ & 1013 & 213 & $1.23(0.81-1.86)$ & 1013 & 122 & $1.25(0.71-2.20)$ \\
\hline $\begin{array}{l}\text { Full case analysis with missing exposure as } \\
\text { category }^{\mathbf{a}}\end{array}$ & 559 & 208 & $1.04(0.72-1.52)$ & 559 & 128 & $1.14(0.71-1.83)$ & 559 & 77 & $0.86(0.44-1.65)$ \\
\hline $\begin{array}{l}\text { Full case analysis (classify missing exposure as } \\
\text { continued smokers) }^{\text {a }}\end{array}$ & 559 & 208 & $1.00(0.70-1.43)$ & 559 & 128 & $1.02(0.66-1.58)$ & 559 & 77 & $0.76(0.41-1.41)$ \\
\hline
\end{tabular}

who were recorded as having stopped smoking may have subsequently relapsed, while some recorded as continuing may subsequently stopped. This mixing of exposure assignment is likely to underestimate the strength of association (Sorahan and Gilthorpe, 1994; Wacholder et al, 1995), but it creates uncertainty. Although we controlled for a range of confounders, we were unable to adjust for all possible confounders. In particular, the data on stage at diagnosis is not recorded in UK primary care notes so this could not be controlled for in the analysis. There is no biologically plausible reason why those who quit smoking after diagnosis would present with more favourable stage than those who continued to smoke. However, it is plausible that presenting with more advanced cancer undermines motivation to stop smoking and that this would confound the association, producing the associations in the direction we observed. In addition, primary care records have limited information on the treatment received and often this was not recorded. Consequently, it was not possible to reliably differentiate those treated curatively from those treated palliatively. We confined the analysis to people who survived at least a year to try to limit this confounding, but this may not have been entirely successful. In addition, SES and alcohol consumption were not well recorded, and more than $20 \%$ of people had missing data for these variables so we used multiple imputation models. These models produced broadly similar results to the models that did not control for these variables.

Interpretation and context with previous literature. Our findings relating to all-cause mortality are consistent with other published literature (Browman et al, 1993; Aveyard et al, 2002; Clark et al, 2006; Mayne et al, 2009; Parsons et al, 2010) We have previously reported a systematic review of studies in lung cancer patients that found that, after adjustment for key prognostic factors, quitting was associated with reduced mortality, with a HR of 0.34 (95\%CI: 0.13-0.87) for non-small cell cancer and 0.54 (95\%CI: 0.39-0.75) for small cell lung cancer (Parsons et al, 2010). Both these estimates were derived from only one study each, with around 200 participants. Our study produced more modest estimates of the benefits of quitting in lung cancer, but the point estimates are within these confidence intervals. Similarly, studies comparing mortality between people who quit smoking after diagnosis of head and neck cancer and people who continue to smoke have found lower mortality risk in those who quit. For example, Mayne et al, 2009 reported a significantly lower risk of mortality (HR: 0.30 95\%CI: 0.16-0.57) (Mayne et al, 2009) and Browman et al, 1993 reported improved two-year survival (66\% vs $39 \%, P=0.005)$. Studies in patients with bladder cancer have compared rates of all-cause mortality in people who smoke at diagnosis to those who have never smoked, or to those who have quit some time before diagnosis, but not to people who quit after diagnosis and therefore there is no evidence from previous studies to compare our results with (Aveyard et al, 2002; Van Osch et al, 2016). In our analysis, we adjusted for common comorbidities, and smoking cessation was still associated with a risk of death due from any cause in lung cancer. There is strong evidence elsewhere that quitting smoking reduces the risk of heart disease and respiratory death (Critchley and Capewell, 2003), including from a clinical trial (Anthonisen et al, 2002), and therefore we conclude that the association between quitting and reduced all-cause mortality in lung cancer is causal.

There is evidence that continued smoking increases risk of a second primary cancer and recurrence (US Surgeon General, 2014a), but the evidence that quitting at the time of diagnosis reduces this risk is relatively weak. For example, in our review of lung cancer patients, both non-small cell and small cell lung cancer patients who quit smoking had a lower risk of recurrence (NSCLC HR: 0.54 (0.29-0.99); SCLC HR: 0.79 (0.67-0.94) and small cell lung cancer patients had a lower risk of second primary tumour although confidence intervals were wide (HR 0.23 (0.05-0.92) (Parsons et al, 2010). Each of these estimates originate from one study only which include a small numbers of patients (Kawahara et al, 1998; Videtic et al, 2003; Nia et al, 2005). Do et al found that in patients with early stage head and neck squamous cell carcinoma, continued smokers and quitters were both more likely to develop second primary tumours than never smokers. However, when indirectly comparing continuing smokers and quitters (Bucher et al, 1997)/ there was no evidence of a difference in 
A

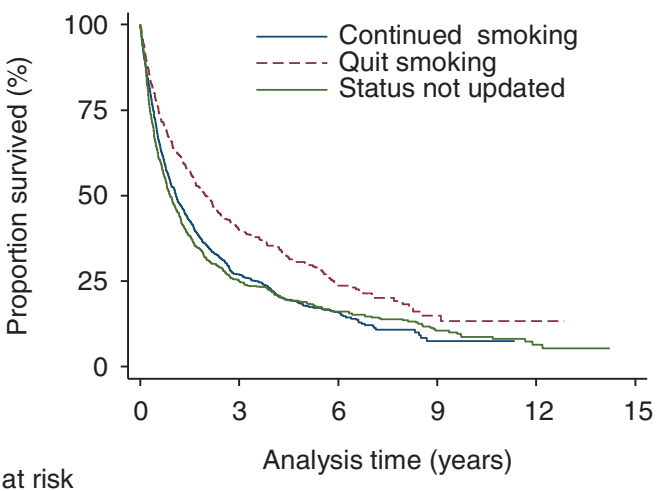

\begin{tabular}{rcccccc} 
Number at risk & \multicolumn{7}{c}{ Analysis time (years) } \\
Continued smoking & 1129 & 184 & 52 & 8 & 0 & 0 \\
Quit smoking & 784 & 187 & 54 & 9 & 1 & 0 \\
Status not updated & 969 & 178 & 74 & 24 & 7 & 0
\end{tabular}

B

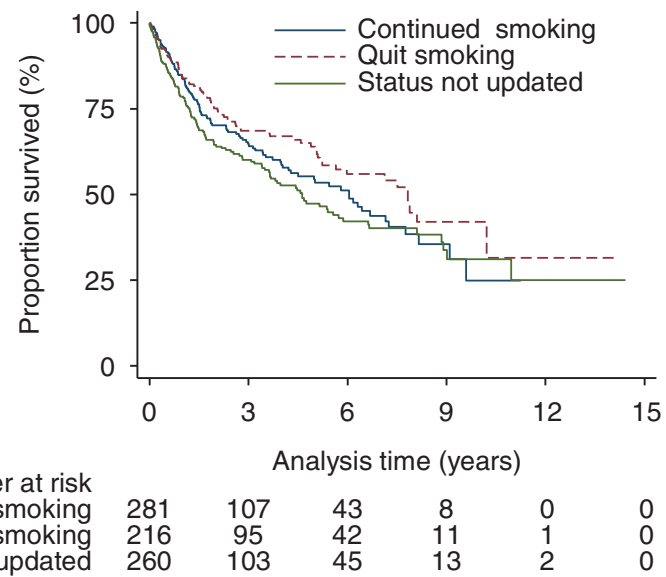

\section{C}

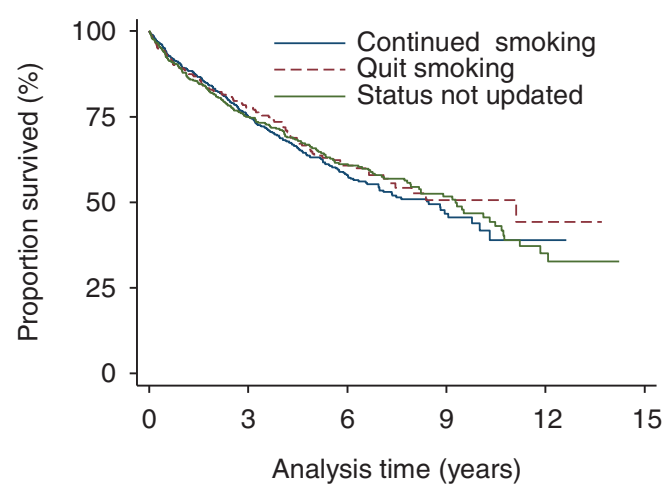

Number at risk

$\begin{array}{rcccccc}\text { Continued smoking } & 850 & 407 & 167 & 46 & 3 & 0 \\ \text { Quit smoking } & 356 & 185 & 75 & 25 & 5 & 0 \\ \text { Status not updated } & 527 & 276 & 143 & 59 & 15 & 0\end{array}$

Figure 2. Unadjusted risk of all-cause mortality in patients who quit smoking compared with those who continued to smoke after diagnosis. (A) Lung cancer; (B) Upper aero-digestive tract cancer; (C) Bladder cancer.

risk (HR 0.94 (95\%CI 0.34-2.60). Leon et al conducted a matched case control study in patients with head and neck cancer and found that quitters had a significantly lower risk of a second primary neoplasm compared with those who continued to smoke (HR 0.34 (95\%CI 0.24-0.56)) (Leon et al, 2009). In patients with superficial transitional cell carcinoma of the bladder, Fleshner et al reported data that allowed us to compare the risk of recurrence in patients
A

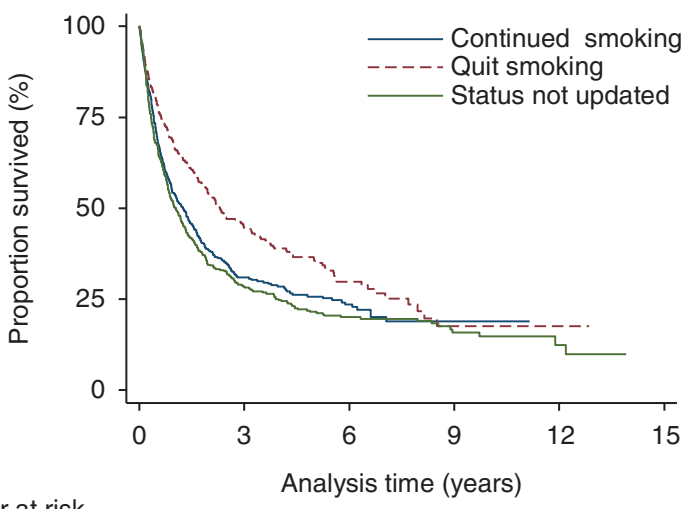

$\begin{array}{rrrrrrr}\text { Number at risk } & 625 & 101 & 35 & 6 & 0 & 0 \\ \text { Cuit smoking } & 466 & 113 & 33 & 6 & 1 & 0 \\ \text { Status not updated } & 544 & 107 & 49 & 17 & 5 & 0\end{array}$

B

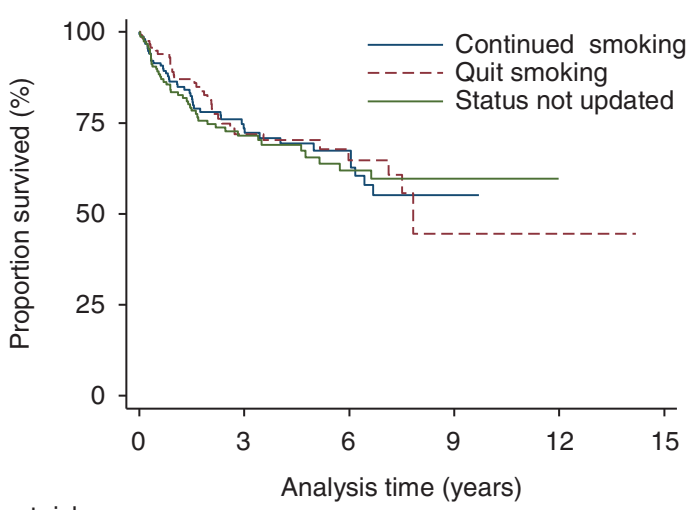

$\begin{array}{rrrrrrr}\text { Number at risk } & & & & & & \\ \text { Continued smoking } & 154 & 59 & 29 & 3 & 0 & 0 \\ \text { Quit smoking } & 120 & 47 & 21 & 5 & 1 & 0 \\ \text { Status not updated } & 154 & 61 & 30 & 8 & 0 & 0\end{array}$

C

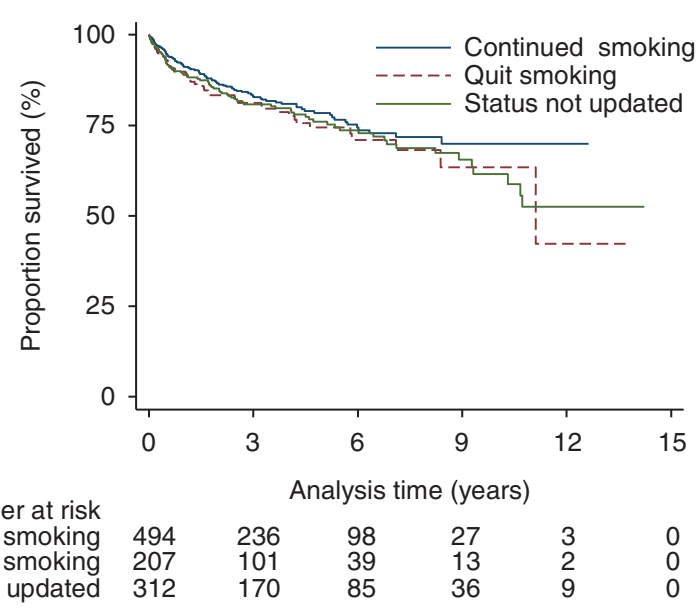

Figure 3. Unadjusted risk of cancer-specific mortality in patients who quit smoking compared with those who continued to smoke after diagnosis. (A) Lung cancer; (B) Upper aero-digestive tract cancer; (C) Bladder cancer.

who quit smoking after diagnosis to those who continued to smoke (Fleshner et al, 1999). Indirect comparison showed quitters were at lower risk of recurrence, but it was not significant (HR $0.71(0.48-$ 1.05)) (Aveyard et al, 2002). Taken together with our findings, the evidence appears inconclusive that quitting smoking lowers the risk of cancer progression in people with bladder cancer. However, overall there is stronger evidence that quitting improves cancer outcomes in UAT and lung cancer. 
A

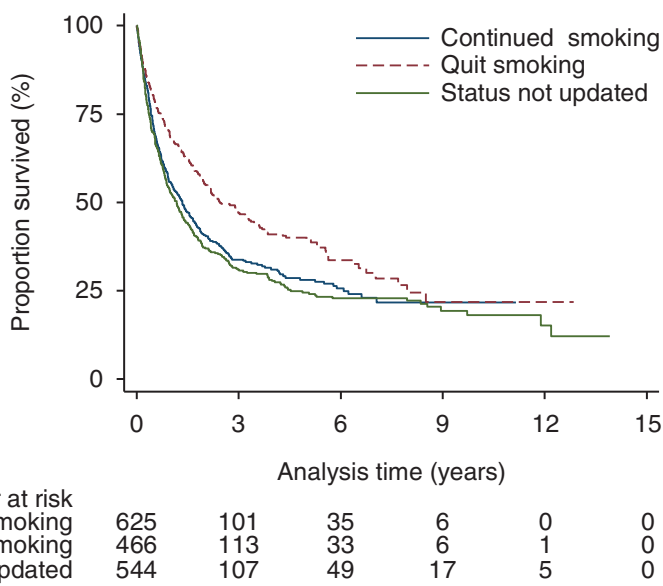

B

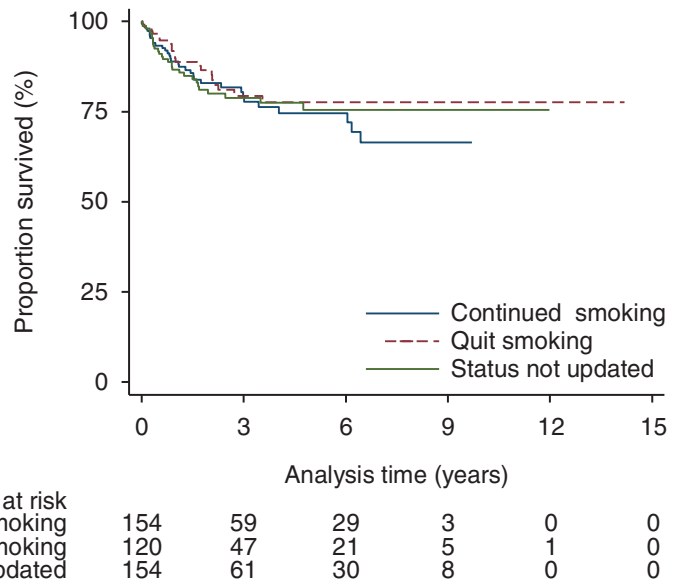

C

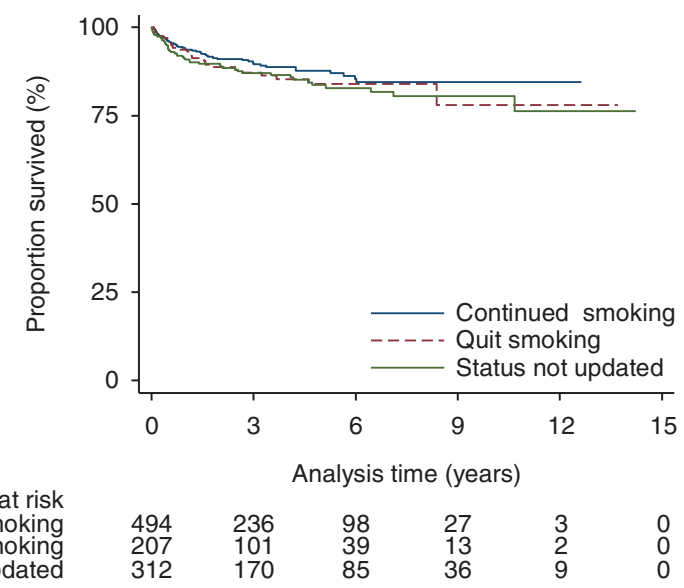

Figure 4. Unadjusted risk of death due to index cancer in patients who quit smoking compared with those who continued to smoke after diagnosis. (A) Lung cancer; (B) Upper aero-digestive tract cancer; (C) Bladder cancer.

There are several potential mechanisms by which continued smoking may affect cancer-specific survival. Previous studies have shown that continued smoking may reduce the effectiveness of adjuvant cancer treatment (Dresler, 2003; Gritz et al, 2005; Zevallos et al, 2009; Chen et al, 2011; Gajdos et al, 2012). For example, tobacco smoke reduces plasma concentrations of chemotherapeutic agents as it is a potent inducer of the cytochrome P450 enzymes which metabolise several drugs in the liver, including some chemotherapies (Dresler, 2003; Petros et al, 2012). In addition to affecting treatment, constituents of tobacco smoke may also alter the behaviour of cancer cells or aid processes that support tumour development and progression (Yoshino and Maehara, 2007; Warren et al, 2014). Cigarette smoke contains many potential irritants and is a strong inflammatory stimulus (Lee et al, 2012; Warren et al, 2014), and evidence is been mounting that an inflammatory microenvironment aids development and progression of tumours (Balkwill and Mantovani, 2001; Aggarwal et al, 2006; Mantovani et al, 2008; Lee et al, 2012). It is possible that these mechanisms may be at play in the increased risk of death associated with continued smoking in lung and UAT cancers.

These results reinforce the need to provide active and ongoing smoking cessation support for people with cancer who smoke which is both a non-toxic and cost-saving intervention for the patient. In addition to reduced survival, previous studies have shown that continued smoking is associated with lower quality of life (Garces et al, 2014) increased pain (Daniel et al, 2009), treatment-related toxicity (Gritz et al, 2014; US Surgeon General, 2014b) and longer length of hospital stay in cancer patients (Erhunmwunsee and Onaitis, 2009). Many patients try to quit on diagnosis (Gritz et al, 1991), so those who relapse find themselves involuntarily trapped by their addiction. The lesson of the Lung Health Study, a study of people who continued smoking despite COPD, is that continued support for smoking cessation, despite early failure to quit, improves outcomes for patients (Scanlon et al, 2000). There is strong evidence that smoking cessation support in hospitalised patients that continues for at least a month after discharge increases rates of cessation (Rigotti et al, 2012). English (NICE) guidance recommends that patients accessing secondary care should be offered support to quit smoking within this setting, and for inpatients, this should include referral to intensive smoking cessation support which continues after discharge (Excellence. NICE, 2013). Despite this, support for smoking cessation is not well integrated into cancer care (Murray et al, 2012; Warren et al, 2013b) and future work should examine interventions to improve the health system to provide treatment for tobacco dependence.

\section{CONCLUSION}

Most lung, UAT and bladder cancer patients who smoke at diagnosis continue smoking. However, quitting smoking reduces the risk of death in lung cancer and may do so in UAT cancer, but there is no evidence in this study that it does so in bladder cancer. The reduction in risk of death may be due to a decreased risk of cancer progression, but this needs further investigation.

\section{ACKNOWLEDGEMENTS}

This study has been presented as an oral presentation at the UK Nicotine and Smoking Cessation Conference, London, June 2016. This work was supported by the NIHR School for Primary Care Research (project number: 224).

\section{CONFLICT OF INTEREST}

Three of our authors report potential conflicts of interest, and the remaining four do not have any to report. The potential conflicts are as follows: Paul Aveyard reports grants from MRC, NIHR, CRUK, ESRC, and UK Centre for Tobacco and Alcohol Studies during the conduct of this study; Amanda Farley reports grants 
from the NIHR and CRUK during the conduct of this study; Ronan Ryan reports that he was part-funded by the National Health Service (Heart of England NHS Foundation Trust) during the conduct of this study.

The funder was not involved in the design and conduct of the study; collection, management, analysis, and interpretation of the data; or preparation, review, or approval of the manuscript. The views expressed are those of the authors and not necessarily those of the NIHR, the NHS or the Department of Health.

\section{AUTHORS CONTRIBUTIONS}

All authors developed and approved the study protocol. CK, JO and RS conducted or supervised the data processing and analysis. Drafting of the manuscript was led by AF, and contributed to by all authors. All authors have approved the final version of the manuscript.

\section{REFERENCES}

Aggarwal B, Shishodia S, Sandur SK, Pandey MK, Sethi G (2006) Inflammation and cancer: How hot is the link? Biochem Pharmacol 72: 1605-1621.

Anthonisen N, Connett JE, Enright PL, Manfreda J. for the Lung Health Study Research Group (2002) Hospitalizations and mortality in the Lung Health Study. Am J Respir Crit Care Med 166(3): 333-339.

Aveyard P, Adab P, Cheng KK, Wallace DM, Hey K, Murphy MF (2002) Does smoking status influence the prognosis of bladder cancer? A systematic review. BJU Int 90(3): 228-239.

Balkwill F, Mantovani A (2001) Inflammation and cancer: back to Virchow? Lancet 357: 539-545.

Balough E, Dresler C, Fleury ME, Gritz ER, Kean TJ, Myers ML, Nass SJ, Nevidjon B, Toll BA, Warren GW, Herbst RS (2014) Reducing tobaccorelated cancer incidence and mortality: summary of an institute of medicine workshop. Oncologist 19: 21-31.

Browman G, Wong G, Hodson I, Sathya J, Russell R, McAlpine L, Skingley P, Levine MN (1993) Influence of cigarette smoking on the efficacy of radiation therapy in head and neck cancer. N Engl J Med 328(3): 159-163.

Bucher H, Guyatt GH, Griffith LE, Walter SD (1997) The results of direct and indirect treatment comparisions in meta-anlaysis of randomized controlled trials. J Clin Epidemiol 50(6): 683-691.

Chen A, Chen LM, Vaughan A, Sreeraman R, Farwell DG, Luu Q, Lau DH, Stuart K, Purdy JA, Vijayakumar S (2011) Tobacco smoking during radiation therapy for head and neck cancer is associated with unfavourable outcome. Int J Rad Oncol Biol Phys 79: 414-419.

Clark T, Murphy MF, Hay K, Drury M, Cheng KK, Aveyard P (2006) Does smoking influence survival in cancer patients through effects on respiratory and vascular disease? Eur J Cancer Prev 15(1): 87-90.

Cooley M, Sarna L, Kotlerman J, Lukanich JM, Jaklitsch M, Green SB, Bueon R (2009) Smoking cessation is challenging even for patients recovering from lung cancer surgery with curative intent. Lung Cancer 66: 218-225.

Critchley J, Capewell S (2003) Mortality risk reduction associated with smoking cessation in patients with coronary heart disease: a systematic review. Jama 290(1): 86-97.

Daniel M, Keefe FJ, Lyna P, Peterson B, Garst J, Kelley M, Belper G, Bastian LA (2009) Persistent smoking after a diagnosis of lung cancer is associated with higher reported pain levels. J Pain 10: 323-328.

De Angelis R, Sant M, Coleman MP, Fancisci S, Baili P, Pierannunzio D, Trama A, Visser O, Brenner H, Ardanaz E, Bielska-Lasota M, Engholm G, Nennecke A, Siesling S, Berrino F, Capocaccia R. EUROCARE-5 Working Group (2014) Cancer Survival in Europe 1999-2007 by country and age: results of EUROCARE-5-a population-based study. Lancet Oncol 15: 23-34.

Dresler C (2003) Is it more important to quit smoking than which chemotherapy is used? Lung cancer 39: 119-124.

Erhunmwunsee L, Onaitis M (2009) Smoking cessation and the success of lung cancer surgery. Curr Oncol Rep 11: 269-274.

Excellence. NICE (2013) NICE guidelines [PH48] Smoking: acute, maternity and mental health services.
Ezzati M, Henley SJ, Lopez AD, Tun MJ (2005) Role of smoking in global and regional cancer epidemiology: current patterns and data needs. Int $J$ Cancer 116: 963-971.

Fleshner N, Garland J, Moadel A, Herr H, Ostroff J, Trambert R, O’sullivan M, Russo P (1999) Influence of smoking status on the disease-related outcomes of patients with tobacco-associated superficial transitional cell carcinoma of the bladder. Cancer 86: 2337-2345.

Gajdos C, Hawn MT, Campagna EJ, Henderson WG, Singh JA, Houston T (2012) Adverse effects of smoking on postoperative outcomes in cancer patients. Ann Surg Oncol 19: 1430-1438.

Garces Y, Yang P, Parkinson J, Zhao X, Wampfler JA, Ebbert JO, Sloan JA (2014) The relationship between cigarette smoking and quality of life after lung cancer diagnosis. CHEST J 126: 1733-1741.

Gritz E, Dresler C, Sarna L (2005) Smoking, the missing drug interaction in clinical trials: ignoring the obvious. Cancer Epidemiol Biomarkers Prevent 14(10): 2287-2293.

Gritz E, Nisenbaum R, Elashoff RE, Holmes EC (1991) Smoking behavior following diagnosis in patients with stage I non-small cell lung cancer. Cancer Causes Control 2(2): 105-112.

Gritz E, Toll BA, Warren GW (2014) Tobacco use in the oncology setting: advancing clinical practice and research. Cancer Epidemiol Biomarkers Prev 23(1): 3-9.

Herrett E, Gallagher AM, Bhaskaran K, Forbes H, Mathur R, van Staa T, Smeeth L (2015) Data Resource Profile: Clinical Practice Research Datalink (CPRD). Int J Epidemiol 44(3): 827-836.

HSCIC (2014).

Kawahara M, Ushijima S, Kamimori T, Kodama N, Ogawara M, Matsui K, Takada M, Sobue T, Furuse K (1998) Second primary tumors in more than 2 year diseasefree survivors of small cell lung cancer in Japan: the role of smoking cessation. Br J Cancer 78: 409-412.

Land S (2012) Methodologic barriers to addressing critical questions about tobacco and cancer prognosis. J Clin oncol 30(17): 2030-2032.

Lee J, Taneja V, Vassallo (2012) Cigarette smoking and inflammation. J Dent Res 91(2): 142-149.

Leon X, del Prado Venegas M, Orus C, Lopez M, Garcia J, Quer M (2009) Influence of the persistence of tobacco and alcohol use in the appearance of second neoplasm in patients with a head and neck cancer. A casecontrol study. Cancer Causes Control 20(5): 645-652.

Mantovani A, Allavena P, Sica A, Balkwill F (2008) Cancer-related inflammation. Nature 454: 436-444.

Marston L, Carpenter JR, Walters KR, Morris RW, Nazareth I, White IR, Petersen I (2014) Smoker, ex-smoker or non-smoker? The validity of routinely recorded smoking status in UK primary care: a cross-sectional study. BMJ Open 4: e004958.

Mayne S, Cartmel B, Kirsh V, Goodwin Jr. WJ (2009) Alcohol and tobacco use prediagnosis and postdiagnosis, and survival in a cohort of patients with early stage cancers of the oral cavity, pharynx, and larynx. Cancer Epidemiol Biomarkers Prev 18(12): 3368-3374.

Murray R, Leonardi-Bee J, Marsh J, Jayes L, Britton J (2012) Smoking status ascertainment and interventions in acute medical patients. Clin Med 12: 59-62.

Nia P, Weyler J, Colpaert C, Vermeulen P, Marck EV, Chil PV (2005) Prognostic value of smoking status in operated non-small cell lung cancer. Lung Cancer 47: 351-359.

Park E, Japuntich SJ, Rigotti NA, Traeger L, He Y, Wallace RB, Malin JL, Zallen JP, Keating NL (2012) A snapshot of smokers after lung and colorectal cancer diagnosis. Cancer 118: 3153-3164.

Parsons A, Daley A, Begh R, Aveyard P (2010) Influence of smoking cessation after diagnosis of early stage lung cancer on prognosis: systematic review of observational studies with meta-analysis. BMJ 340: b5569.

Petros W, Younis IR, Ford JN, Weed SA (2012) Effects of tobacco smoking and nicotine on cancer treatment. Pharmacotherapy 32(10): 920-931.

Rigotti N, Munafo MR, Stead LF (2012) Interventions for smoking cessation in hospitalised patients. Cochrane Database Syst Rev5): CD001837.

Scanlon P, Connett JE, Waller LA, Altose MD, Bailey WC, Buist AS, Tashkin DP. for the Lung Health Study Research Group (2000) Smoking cessation and lung function in mild-to-moderate chronic obstructive pulmonary disease. Am J Respir Crit Care Med 161(2): 381-390.

Sorahan T, Gilthorpe MS (1994) Non-differential misclassification of exposure always leads to an underestimate of risk: an incorrect conclusion. Occup Environ Med 51(12): 839-840.

Thun M, DeLancey JO, Center MM, Jemal A, Ward EM (2009) The global burden of cancer: priorities for prevention. Carcinogenesis 31(1): 100-110. UK. CR (2016) Lung cancer survival statistics. 
US Surgeon General (2014a) The Health Consequences of Smoking-50 Years of Progress: A Report of the Surgeon General. US Department of Health and Human Services.

US Surgeon General (2014b) The health consequences of tobacco smoke- 50 years on: a report of the surgeon general. Available at: http:// www.surgeongeneral.gov/library/reports/50-years-of-progress/.

Van Osch F, Jochems, SHJ., van Schooten FJ, Bryan RT, Zeegers MP (2016) Significant role of lifetime cigarette smoking in worsening bladder cancer and upper tract urothelial carcinoma prognosis: A Meta-Analysis. J Urol 195: 1-8.

Verdecchia A, Francisci S, Brenner H, Gatta G, Micheli A, Mangone L, Kunkler I. EUROCARE-4 Working Group (2007) Recent cancer survival in Europe: a 2000-02 period analysis of EUROCARE-4 data. Lancet Oncol 8: 784-796.

Videtic G, Stitt LW, Dar AR, Kocha WI, Tomiak AT, Truong PT, Vincent MD, Yu EW (2003) Continued cigarette smoking by patients receiving concurrent chemoradiotherapy for limited-stage smallcell lung cancer is associated with decreased survival. J Clin Oncol 21: 1544-1549.

Wacholder S, Hartge P, Lubin JH, Dosemeci M (1995) Non-differential misclassification and bias towards the null: a clarification. Occup Environ Med 52(8): 557-558.

Walters S, Maringe C, Coleman MP, Peake MD, Butler J, Young N, Bergstrom S, Hanna L, Jakobsen E, Kolbeck K, Sundrom S, Engholm G, Gavin A, Gjerstorff ML, Hatcher J, Johannesen TB, Linklater KM, McGahan CE, Steward J, Tracey E, Turner D, Richards MA, Rachet B. ICBP Module 1 Working Group (2013) Lung cancer survival and stage at diagnosis in Australia, Canada, Denmark, Norway, Sweden and the UK: a population-based study, 2004-2007. Thorax 68(6): 551-564.
Warren G, Kasza KA, Reid ME, Cummings M, Marshall JR (2013a) Smoking at diagnosis and survival in cancer patients. Int J Cancer 132: 401-410.

Warren G, Marshall JR, Cummings KM, Toll BA, Gritz ER, Hutson A, Dibaj S, Herbst R, Mulshine JL, Hanna N, Dresler CA (2013b) Addressing tobacco use in patients with cancer: a survey of American society of clinical oncology member. J Oncol Pract 9(5): 258-262.

Warren G, Sobus S, Gritz E (2014) The biological and clinical effects of smoking by patients with cancer and strategies to implement evidencebased tobacco cessation support. Lancet Oncol 15: e568-e580.

White I, Royston P (2009) Imputing missing covariate values for the Cox model. Stat Med 28(15): 1982-1998.

Yoshino I, Maehara Y (2007) Impact of smoking status on the biological behavior of lung cancer. Surg Today 37(9): 725-734.

Zevallos J, Mallen MJ, Lam CY, Karam-Hage M, Blalock J, Wetter DW, Garden AS, Sturgis EM, Cinciripini PM (2009) Complications of radiotherapy in laryngopharyngeal cancer: effects of a prospective smoking cessation program. Cancer 115: 4636-4644.

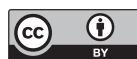

This work is licensed under the Creative Commons Attribution 4.0 International License. To view a copy of this license, visit http://creativecommons.org/licenses/by/4.0/

(C) The Author(s) named above 2017 